\title{
Managing comorbidities in COPD
}

This article was published in the following Dove Press journal:

International Journal of COPD

7 January 2015

Number of times this article has been viewed

\author{
Georgios Hillas' \\ Fotis Perlikos ${ }^{1}$ \\ loanna Tsiligianni ${ }^{2,3}$ \\ Nikolaos Tzanakis ${ }^{2}$ \\ 'Department of Critical Care and \\ Pulmonary Services, University of \\ Athens Medical School, Evangelismos \\ Hospital, Athens, ${ }^{2}$ Department of \\ Thoracic Medicine, University \\ Hospital of Heraklion, Medical School, \\ University of Crete, Crete, Greece; \\ ${ }^{3}$ Department of General Practice, \\ University Medical Centre \\ of Groningen, Groningen, \\ The Netherlands
}

Abstract: Chronic obstructive pulmonary disease (COPD) is a leading cause of morbidity and mortality worldwide. Age and smoking are common risk factors for COPD and other illnesses, often leading COPD patients to demonstrate multiple coexisting comorbidities. COPD exacerbations and comorbidities contribute to the overall severity in individual patients. Clinical trials investigating the treatment of COPD routinely exclude patients with multiple comorbidities or advanced age. Clinical practice guidelines for a specific disease do not usually address comorbidities in their recommendations. However, the management and the medical intervention in COPD patients with comorbidities need a holistic approach that is not clearly established worldwide. This holistic approach should include the specific burden of each comorbidity in the COPD severity classification scale. Further, the pharmacological and nonpharmacological management should also include optimal interventions and risk factor modifications simultaneously for all diseases. All health care specialists in COPD management need to work together with professionals specialized in the management of the other major chronic diseases in order to provide a multidisciplinary approach to COPD patients with multiple diseases. In this review, we focus on the major comorbidities that affect COPD patients. We present an overview of the problems faced, the reasons and risk factors for the most commonly encountered comorbidities, and the burden on health care costs. We also provide a rationale for approaching the therapeutic options of the COPD patient afflicted by comorbidity.

Keywords: chronic obstructive pulmonary disease, comorbid major diseases, management, treatment, health care costs

\section{Introduction}

Chronic obstructive pulmonary disease (COPD) is a leading cause of morbidity and mortality worldwide, especially among smokers over 40 years of age and individuals exposed to biomass smoke. ${ }^{1}$ The World Health Organization estimates that COPD will be the third most common worldwide cause of death and disability by 2030 , from its current fifth ranking. ${ }^{2}$ Despite worldwide medical research, health care efforts, and health care costs, COPD statistics reveal a continuing upward trend in mortality, in contrast with other major causes of death like cancer and cardiovascular disease. ${ }^{2} \mathrm{~A}$ major factor that complicates therapeutic approaches to the management of COPD is that COPD is rarely the only chronic illness a patient has to contend with. Age and smoking are the major risk factors for COPD and a number of other illnesses, often leading to COPD patients demonstrating multiple coexisting comorbidities.,

The presence of comorbidities is so strongly associated with the management of COPD that the need for thorough attention to them is emphasized even in the
Correspondence: Nikolaos Tzanakis Department of Thoracic Medicine, Medical School, University of Crete, 7I 003 Heraklion, Greece

Tel +30-6984643636

Email tzanakis@med.uoc.gr
Dovepress

http://dx.doi.org/10.21 477/COPD.S54473
International Journal of COPD 2015:10 95-109

(c) (1) (2) ( 2015 Hillas et al. This work is published by Dove Medical Press Limited, and licensed under Creative Commons Attribution - Non Commercial (unported, v3.0)

95

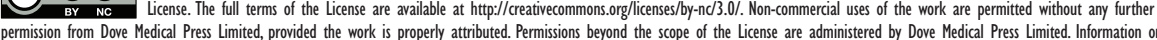
permission from Dove Medical Press Limited, provided the work is properly attributed. Permissions beyond the scope of the License are administered by Dove Medical Press Limited. Information on
how to request permission may be found at: http://www.dovepress.com/permissions.php 
COPD definition by GOLD (Global Initiative for Chronic Obstructive Lung Disease) guidelines: 5 "Chronic obstructive pulmonary disease, a common preventable and treatable disease, is characterized by airflow limitation that is usually progressive and associated with an enhanced chronic inflammatory response in the airways and the lung to noxious particles or gases. Exacerbations and comorbidities contribute to the overall severity in individual patients." Comorbidities are most often responsible for impairing quality of life for early-stage patients, ${ }^{6}$ for increasing mortality in end-stage patients, for increasing the burden of COPD management on health care costs, and creating therapeutic dilemmas for health care providers. ${ }^{5}$

COPD comorbidities is a rather broad heterogeneous term, including diseases that independently coexist with COPD with no other causation, diseases that share common risk factors and pathogenetic pathways with COPD, diseases that are complicated by the interaction with the lung, and systemic manifestations of COPD, and vice versa. This heterogeneity has given rise in recent years to a conceptual discussion about the appropriateness of the term "comorbidities", in an attempt to establish an agreement over its meaning. No universal definition has yet been accepted. Terminology issues though should not shift our focus from the fact that COPD patients with multiple diseases often have poorer outcomes and are in need of a more complex, tailored therapeutic intervention approach ${ }^{7,8}$ in order to optimize and achieve better outcomes.

For this review, we consider as common comorbidities all previously described diseases that frequently coexist with COPD, without discriminating between those directly related and those not. The underlying causes of multimorbidity in COPD are not yet fully recognized. There is an increasing abundance of evidence that associates COPD with other agedriven diseases and diseases that share common risk factors (smoking) or etiological pathways. ${ }^{3}$ This view is supported by the widely accepted hypothesis that COPD sustains systematic inflammation. ${ }^{9}$ Most commonly COPD is associated with lung cancer and other cancers, asthma, obstructive sleep apnea syndrome, hypertension, cardiovascular disease, diabetes, metabolic syndrome, dysfunctional skeletal myopathies, osteoporosis, and mental disorders. Although these associations are part of our established knowledge about the disease, precise prevalence numbers differ in the published epidemiological studies (see Table 1). ${ }^{3}$ There is a need to identify from the extensive pool of comorbidities those which are more strongly associated with a significantly increased risk of death in COPD individuals. Divo et al in a
Table I Prevalence of the most common COPD comorbidities (\%)

\begin{tabular}{|c|c|c|c|c|c|}
\hline Study & Cancer & CVD & HTN & DM & $\begin{array}{l}\text { Mental } \\
\text { disorders* }\end{array}$ \\
\hline Anecchino et al ${ }^{175}$ & - & 68 & - & 12 & 8 \\
\hline Cazzola et $\mathrm{al}^{66}$ & 2 & - & - & 19 & 42 \\
\hline Koskela et $\mathrm{al}^{6}$ & 6 & 27 & 41 & 18 & 45 \\
\hline Frei et al ${ }^{153}$ & 14 & 20 & 42 & 16 & 25 \\
\hline Fumagalli et al ${ }^{147}$ & 13 & - & 52 & 11 & $13(F)$ \\
\hline Mapel et al ${ }^{139}$ & 18 & 65 & 45 & 12 & - \\
\hline Miyazaki et al ${ }^{150}$ & 25 & 32 & 36 & 15 & 17 \\
\hline Sidney et a $\left.\right|^{35}$ & - & 18 & 18 & 2 & - \\
\hline Soriano et al ${ }^{12}$ & 4 & 22 & - & - & - \\
\hline Lopez Varela et al ${ }^{176}$ & 8 & 41 & 37 & 8 & - \\
\hline van Manen et al ${ }^{177}$ & - & 13 & 23 & 5 & 25 \\
\hline
\end{tabular}

Note: *Mental disorders include anxiety and depression.

Abbreviations: F, female; CVD, cardiovascular disease; HTN, hypertension; DM, diabetes mellitus; COPD, chronic obstructive pulmonary disease.

recent report concluded that lung, pancreatic, esophageal, and breast cancers (the last only for female patients), pulmonary fibrosis, atrial fibrillation/flutter, congestive heart failure, coronary artery disease, gastric/duodenal ulcers, liver cirrhosis, diabetes with neuropathy, and anxiety are the most significant and frequent comorbidities. ${ }^{10}$ Clinical practice guidelines usually mention but seldom address comorbidities practically in their recommendations. Furthermore, clinical trials investigating COPD treatment routinely exclude patients with multiple comorbidities or advanced age ${ }^{11}$ the latter enormously affects the external validity and generalizability of the effectiveness of the treatments tested in the large clinical trials.

In this review, we focus on the major comorbidities that affect COPD patients, present an overview of the problems they face, the reasons and risk factors for the most commonly encountered comorbidities (Figure 1), the burden on health care costs, and provide a rationale for approaching the therapeutic options for the COPD patient afflicted by comorbidity.

\section{Respiratory comorbidities Asthma}

Both asthma and COPD are major chronic obstructive airway diseases that involve underlying airway inflammation. COPD is characterized by airflow limitation that is not fully reversible, is usually progressive, and is associated with an abnormal inflammatory response of the lungs to noxious particles or gases. Individuals with asthma who are exposed to noxious agents (particularly cigarette smoking) may develop fixed airflow limitation and a mixture of "asthma-like" inflammation and "COPD-like" inflammation. Thus, even though 


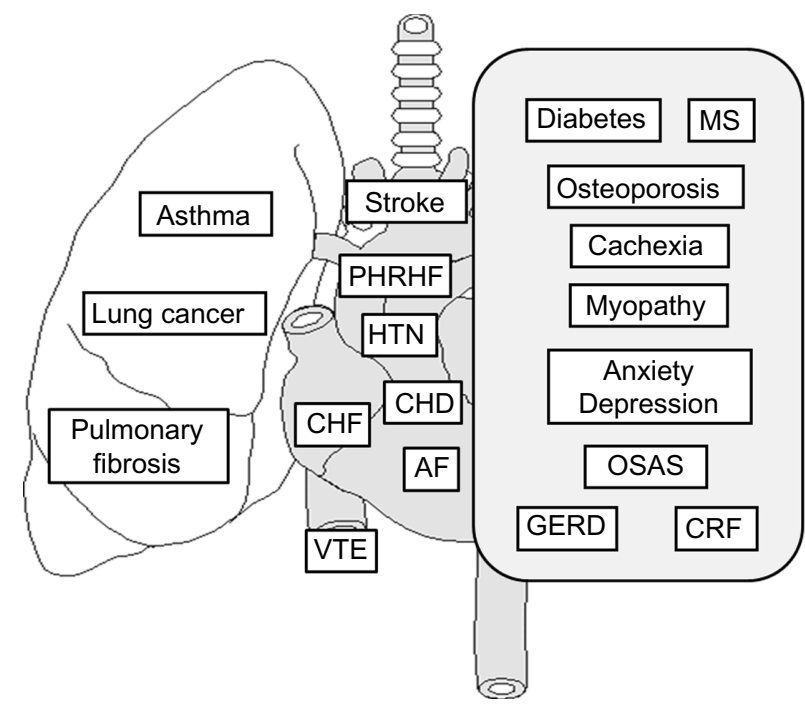

Figure I The most common and clinically important comorbidities in patients with COPD.

Abbreviations: PHRHF, pulmonary hypertension and right heart failure; HTN, hypertension; $\mathrm{CHF}$, congestive heart failure; $\mathrm{CHD}$, coronary heart disease; AF, atrial fibrillation; VTE, venous thromboembolism; MS, metabolic syndrome; OSAS, obstructive sleep apnea syndrome; GERD, gastroesophageal reflux disease; CRF chronic renal failure; COPD, Chronic Obstructive Pulmonary Disease.

asthma can usually be distinguished from COPD, in some individuals who develop chronic respiratory symptoms and fixed airflow limitation, it may be difficult to differentiate the two diseases. In some patients with chronic asthma, a clear distinction from COPD is not possible using current imaging and physiological testing techniques, and it is assumed that asthma and COPD coexist in these patients. In these cases, current management includes use of anti-inflammatory drugs, and other therapies need to be individualized. Other potential diagnoses are usually easier to distinguish from COPD. ${ }^{5}$

Coexistence of asthma and COPD in elderly patients is often diagnosed. ${ }^{12}$ In some studies, the overlap diagnosis of asthma and COPD exceeds half of the patients examined. ${ }^{13,14}$ The overlap is identified by finding increased variability of airflow in patients with incompletely reversible airway obstruction..$^{15}$ The presence of COPD-asthma overlap syndrome is associated with impaired quality of life and more frequent and severe exacerbations compared with COPD only patients. ${ }^{16}$

The coexistence of asthma and COPD cannot be excluded even in the study populations of the biggest COPD clinical trials. In UPLIFT, a 4-year trial of tiotropium in COPD, 5,993 patients were enrolled. ${ }^{17}$ At visit 2 of the study, prebronchodilator spirometry was performed and the patients then received an enhanced bronchodilation test including four inhalations of ipratropium ( $80 \mathrm{mg}$ via metered-dose inhaler) followed 60 minutes later by four inhalations of salbutamol (400 mg via metered-dose inhaler) to ensure maximal or near-maximal bronchodilation. The majority of the study population with moderate-to-very severe COPD demonstrated meaningful increases in lung function following administration of inhaled anticholinergic plus sympathomimetic bronchodilators: $65.6 \%$ of the patients met the criterion of $\mathrm{a} \geq 15 \%$ increase in forced expiratory volume in one second $\left(\mathrm{FEV}_{1}\right)$ and $53.9 \%$ met the criterion of an increase in $\mathrm{FEV}_{1}$ of both $\geq 12 \%$ and $\geq 200 \mathrm{~mL}^{18}$

In ECLIPSE, a large observational study (2,138 COPD patients), researchers tested the hypothesis that there is a frequent-exacerbation phenotype of COPD that is independent of disease severity. ${ }^{19}$ The single best predictor of exacerbations, across all GOLD stages, was a history of exacerbations. The second strongest predictor of exacerbations was a history of reflux or heartburn, a common symptom among asthma patients.

Although the overlap syndrome seems to be a common clinical presentation, both the major COPD guidelines (GOLD) and asthma guidelines (GINA, Global Initiative for Asthma) do not give specific recommendations for its combined treatment at the moment.

In August 2014, a joint project regarding the diagnosis of diseases of chronic airflow limitation (Asthma, COPD, and Asthma-COPD overlap syndrome [ACOS] ) was published by the science committees of GOLD and GINA. ${ }^{20}$ This document was based on a detailed review of available literature and consensus. It provides an approach to distinguishing between asthma, COPD, and the overlap of asthma and COPD, for which the term ACOS is proposed. A stepwise approach to diagnosis is advised, comprising recognition of the presence of a chronic airways disease, syndromic categorization as asthma, COPD, or ACOS, confirmation by spirometry and, if necessary, referral for specialized investigations.

\section{Lung cancer}

COPD patients run an increased risk of developing lung cancer. It is also a factor that contributes to poorer outcomes in lung cancer patients. ${ }^{20,21}$ The prevalence of COPD among patients with lung cancer varies from $40 \%$ to $70 \%{ }^{22,23}$ Lung cancer patients tend to have more severe lung function impairment. Several reports confirmed that lung cancer occurs in COPD patients late in the natural course of the disease. The prevalence of moderate-to-very severe disease (GOLD stages II-IV) among lung cancer patients reaches $50 \%$, in contrast with only $8 \%$ of smokers without lung cancer. ${ }^{20}$ The annual incidence of lung cancer is four times higher in COPD patients when compared with the general population. ${ }^{20,24}$ 
Both diseases create management difficulties for one another, but therapy for lung cancer is more crucially affected. Mainly due to impaired lung function, patients with COPD often fail to meet the tolerance criteria for undergoing surgical resection of their otherwise operable malignancy. The result is that the overall prognosis for patients with both diseases is worse than each alone. Three-year survival in patients with COPD and lung cancer has been found to be around $15 \%$, compared with $26 \%$ for lung cancer patients without COPD. ${ }^{20}$ Lung cancers, together with cardiovascular comorbidities, are the leading causes of death in COPD patients with mild-to-moderate disease, while respiratory failure due to airway obstruction only becomes predominant in advanced COPD. ${ }^{25-27}$

\section{Pulmonary fibrosis}

Pulmonary fibrosis is more common among smokers, and in coexistence with emphysema it has been classified as a distinct clinical entity (combined pulmonary fibrosis and emphysema syndrome) ${ }^{28}$ Patients with coexistence of pulmonary interstitial fibrosis and COPD present characteristic lung function tests, with relatively normal spirometry and lung volumes but severely impaired gas exchange. This results from the inverse effect of airway traction of pulmonary fibrosis on bronchus constriction of COPD. Simultaneously, gas exchange is impaired by both thickening of the alveolar membrane in pulmonary fibrosis and reduction of the vascular surface in emphysema. Compared with pulmonary fibrosis or emphysema alone, patients with combined pulmonary fibrosis and emphysema syndrome have more frequent and more severe pulmonary hypertension. Patients with the syndrome face a reduced survival prognosis compared with patients with COPD, with an estimated median survival of 6 years. ${ }^{24,29}$

\section{Cardiovascular comorbidities Hypertension}

Hypertension is very common in COPD patients, but is not associated with increased mortality. ${ }^{10}$ Hypertension is related to the increased systemic inflammation observed in COPD and is correlated with higher Medical Research Council dyspnea scores, reduced capacity for physical activity, ${ }^{30}$ and airflow obstruction. ${ }^{31}$

\section{Congestive heart failure}

Congestive heart failure and COPD share similar risk factors, especially whatever risk factor is associated with smoking, and common pathophysiological mechanisms, which frequently coexist in the same patient. ${ }^{32}$ The prevalence of congestive heart failure among COPD patients varies between stable disease and exacerbations. In stable COPD studies report a $3.8 \%$ to $16 \%$ coexistence compared with exacerbations that reach up to $48 \%{ }^{33,34}$ Congestive heart failure is among the leading causes of hospitalization and death for patients with COPD and worsens their prognosis. ${ }^{35}$ Simultaneously, COPD is an independent risk factor for death in patients with congestive heart failure. ${ }^{36}$ Coexistence of COPD and congestive heart failure worsens right ventricular dysfunction, when compared with non-COPD patients. ${ }^{37} \mathrm{Left}$ ventricular dysfunction is present in around $20 \%$ of COPD patients, but frequently goes unnoticed..$^{38}$

\section{Coronary heart disease}

COPD and coronary heart disease share a common major risk factor, which is smoking. The coexistence has been reported to be as high as $30 \%$ or even higher in COPD patients. Vigilance in recognizing and diagnosing coronary disease signs and symptoms is needed in assessing COPD patients. ${ }^{39}$ In some studies of the medical records of COPD patients, undiagnosed cases of coronary heart disease reach $70 \%{ }^{40}$ Addressing undiagnosed cases is crucial for improving outcomes, since the coexistence of both diseases worsens the prognosis when compared with each separately. Both diseases are characterized by chronic sustained inflammation and coagulopathy. The key mediator of this sustained inflammation in COPD is probably elevated C-reactive protein levels, which not only maintain bronchial constriction but also increase the risk for coronary disease. ${ }^{24,41}$

\section{Atrial fibrillation}

Atrial fibrillation and COPD are two common morbidities and often coexist. ${ }^{42}$ The presence and severity of COPD are associated with increased risk for atrial fibrillation/ atrial flutter and non-sustained ventricular tachycardia. The prevalence of atrial fibrillation and non-sustained ventricular tachycardia among COPD patients has been reported to be as high as $23.3 \%$ and $13.0 \%$, respectively ${ }^{43}$ Reduced $\mathrm{FEV}_{1}$ and COPD are associated with a higher incidence of atrial fibrillation after adjustment for confounders. ${ }^{44}$ The prevalence of COPD in patients with atrial fibrillation reaches $18 \%{ }^{45}$ Hospitalization mortality in severe COPD patients with arrhythmia has been reported to be as high as $31 \%$, compared with $8 \%$ in non-COPD patients. ${ }^{46}$ Prolonged conduction time in the right atrium and typical atrial flutter are commonly observed in COPD patients with atrial fibrillation. ${ }^{47}$ 


\section{Pulmonary artery hypertension and subsequent right heart failure}

Pulmonary artery hypertension and subsequent right heart failure are observed in COPD patients as a consequence of pulmonary artery remodeling. This remodeling occurs in COPD due to endothelial dysfunction, clotting abnormalities, hypoxic vasoconstriction, destruction of the pulmonary capillary bed, inflammatory infiltration of the vascular wall, and shear stress due to blood flow redistribution. ${ }^{48}$ Reports estimate that the prevalence of pulmonary artery hypertension in COPD patients is as high as $40 \% .{ }^{49}$ When COPD patients develop pulmonary artery hypertension, they experience more intense shortness of breath, greater desaturation during exercise, and more profound limitation of physical activity. The coexistence of COPD and pulmonary artery hypertension is associated with higher mortality. ${ }^{50}$ Signs and symptoms of right ventricular dysfunction should be recognized, although diagnosis of pulmonary artery hypertension does not improve management outcomes in COPD. Addition of long-term oxygen therapy has a stabilizing effect in some patients. ${ }^{24,51}$

\section{Venous thromboembolism}

The prevalence of venous thromboembolism in COPD patients during an exacerbation has been reported to be as high as $29 \% .^{52,53}$ The prevalence of pulmonary embolism in COPD patients is also documented to be higher than in nonCOPD patients and increases with age. ${ }^{54}$ The risk of venous thromboembolism is higher in patients with COPD and other comorbidities like hypertension, coronary artery disease, or cancer, or with previous surgery. Venous thromboembolism prolongs hospitalization by 4.4 days and increases one-year mortality by $30 \% \cdot{ }^{53}$ If not diagnosed and treated adequately, the risk of death during hospitalization for exacerbations is increased by $25 \%$. COPD not only shares certain common risk factors with venous thromboembolism, like smoking, but also systemic inflammation due to COPD induces pulmonary $^{55}$ and systemic endothelial dysfunction ${ }^{56}$ and coagulopathy. ${ }^{24,57,58}$

\section{Stroke}

COPD patients present an increased risk for ischemic stroke, as a result of common risk factors, like age and smoking, and the systemic inflammation and coagulopathy caused by COPD. ${ }^{59,60}$ There is a linear correlation between stroke risk and airflow obstruction. ${ }^{61}$ Almost $8 \%$ of all COPD patients have a history of stroke. ${ }^{62}$ About $4 \%$ of all deaths in COPD patients are related to an incident of ischemic stroke. ${ }^{63}$

\section{Metabolic comorbidities Diabetes and metabolic syndrome}

Diabetes has been reported in several studies to be a frequent COPD comorbidity, with a prevalence as high as $18.7 \%$ among COPD patients. ${ }^{64,65}$ The prevalence of metabolic syndrome is reported to be up to $22.5 \%$ in COPD patients. COPD patients have a relatively increased risk of developing diabetes, ${ }^{66,67}$ but also diabetes often presents before diagnosis of COPD, and diabetic patients have an increased risk of developing COPD.$^{68}$ This side-by-side development of both diseases is a result of common risk factors, like smoking, and also the synergic effect of systemic inflammation mediated by common cytokines. ${ }^{69-71}$ Diabetes worsens the outcomes of COPD by affecting a number of parameters: ${ }^{66,72,73}$ shortening time to first hospitalization and increasing hospitalization time and risk of death during exacerbations, ${ }^{74}$ increasing Medical Research Council dyspnea scores, and reducing sixminute walking distance. ${ }^{30}$ Diabetes worsens 5 -year mortality in COPD patients..$^{24,66}$

\section{Osteoporosis}

Osteoporosis is another chronic illness that frequently coexists with COPD, even in male patients. ${ }^{75,76}$ The prevalence of osteoporosis among COPD patients ranges up to $69 \%$ in some reports, reflecting not only common risk factors, like age and cigarette smoking, but also the harmful effects of COPD due to systemic inflammation, reduced physical activity, and in some cases oral steroid therapy. ${ }^{77}$ At the same time, vertebral fractures due to osteoporosis lead to decreased rib mobility and frequently to kyphosis, which further impairs lung mechanics. ${ }^{78}$ Even asymptomatic vertebral fractures accelerate lung function decline. ${ }^{79}$ Osteoporosis is associated with higher dyspnea scores and reduced six-minute walking distance. ${ }^{30}$ Patients with COPD and osteoporosis tend to have lower body mass index values and more severe airway obstruction. ${ }^{80}$

\section{Cachexia and myopathy}

Loss of fat-free mass (cachexia) and skeletal muscle dysfunction (myopathy) are common comorbidities with COPD. Both are more common in northern countries, compared with the Mediterranean, probably as a result of dietary differences. ${ }^{11}$ The prevalence of cachexia among COPD patients ranges from $10 \%$ to $15 \%$ in mild-to-moderate disease to up to $50 \%$ in severe disease, ${ }^{81}$ even in obese patients. ${ }^{82}$ The prevalence of skeletal muscle weakness has been reported to be as high as 32\% among COPD patients. ${ }^{83}$ Skeletal muscle weakness shares common risk factors with COPD, like age 
and smoking, but is also affected by systemic manifestations of COPD, like systemic inflammation, oxidative stress, and physical inactivity. ${ }^{84}$ Skeletal muscle weakness is associated with reduced strength, endurance and exercise capacity, lack of physical activity, impaired quality of life, increased risk for hospital admission after exacerbation, increased health care utilization, and increased risk of death. ${ }^{85-87}$ Early onset of muscle weakness may reflect a more aggressive COPD phenotype. $^{11}$

\section{Mental comorbidities}

Anxiety and depression frequently accompany certain chronic illnesses. ${ }^{88-90}$ Many COPD patients experience transitory mood symptoms during exacerbations, which improve spontaneously after recovery. Identifying COPD patients with clinical depression and/or anxiety remains a challenge. ${ }^{91}$

Anxiety is also more frequent among COPD patients, compared with the general population or patients with other chronic illnesses, with a prevalence reported to be as high as $19 \% .^{92}$ Patients with anxiety tend to have their first hospitalization earlier in the natural course of COPD, ${ }^{93}$ they are earlier and more intensely irritated by their shortness of breath, and have higher rates of mortality and readmission after an exacerbation. ${ }^{94}$ Anxiety is one of the known comorbidities with the highest risk of death, especially among female patients, ${ }^{95}$ that needs adequate attention as it is a potentially treatable condition. ${ }^{96}$

The prevalence of depression in COPD patients receiving long-term oxygen therapy reaches as high as $60 \%{ }^{97}$ Depression reduces physical activity, quality of life scores, ${ }^{98,99}$ and adherence to medical treatment, ${ }^{100}$ and is associated with higher rates of COPD exacerbations ${ }^{101,102}$ and increased mortality. ${ }^{103}$ Almost 25\% of all COPD patients suffer from depression that eludes diagnosis, ${ }^{104}$ and an estimated two thirds of patients with coexistent COPD and depression do not receive any antidepressant treatment. ${ }^{88,105}$

\section{Other comorbidities}

\section{Obstructive sleep apnea syndrome}

Obstructive sleep apnea syndrome (OSAS) is no more common in COPD that in the general population, as previously believed. Results from the Sleep Heart Health Study, after stratification for body mass index and age, give a prevalence for OSAS of around 14\% among COPD patients 40 years and older. ${ }^{106}$ However, the fact that OSAS is a common clinical entity in the general population gives a significant number of cases of coexistence with COPD. The combination leads to increased risk of death ${ }^{107,108}$ due to more frequent exacerbations and an increased risk for development of cardiovascular comorbidities like pulmonary hypertension and right heart failure. ${ }^{24,109}$

\section{Gastroesophageal reflux disease}

Gastroesophageal reflux disease (GERD) is commonly associated with asthma. Little attention has been paid to symptoms of GERD in COPD patients. Studies show a significant prevalence of GERD in up to $60 \%$ of COPD patients, ${ }^{110-112}$ which is correlated more with quality of life scores on the COPD Assessment Test than with airway obstruction ${ }^{113}$ and risk for exacerbation. ${ }^{19,114}$ These findings raise more questions as to whether COPD patients are dealing with an independent comorbidity or if there is an unnoticed strong asthma component in their disease.

\section{Chronic renal failure}

Renal complications of COPD are common, especially in patients with hypoxemia and hypercapnea. ${ }^{115}$ The arterial rigidity and endothelial dysfunction caused by COPD frequently lead to a decreased normal renal functional reserve. ${ }^{116}$ Impairment of renal functional reserve in COPD patients is correlated with more severe airway obstruction and inflammation. ${ }^{116}$ COPD patients have approximately twice the incidence of acute renal failure, and three times the prevalence of diagnosed chronic renal failure than agematched and gender-matched controls. ${ }^{115}$ Renal insufficiency may be present in around $22 \%$ of COPD patients. ${ }^{117}$ Chronic renal failure often goes undiagnosed, and is a particular concern in elderly COPD patients and in COPD patients with cachexia. ${ }^{118}$ Among COPD patients over 64 years of age, $25 \%$ may have chronic renal failure even with normal serum creatinine values. ${ }^{97}$

\section{Links between COPD and comorbidities}

COPD comorbidities include clinical conditions that share common risk factors and pathogenetic pathways with COPD, ie, diseases that are consequences of COPD and diseases that just coexist with COPD due to their large prevalence in the general population but affect outcomes such as hospitalization rates and mortality. As our knowledge of COPD and of the pathogenesis of COPD comorbidities is gradually elucidated by basic science data, the more the complexity of the interactions involved becomes apparent. As COPD becomes more and more understood as a systematic inflammatory disease, our focus is shifting from the lungs. ${ }^{119}$ 
Smoking and biomass exposure, along with genetic predisposition, are the major risk factors for developing COPD. ${ }^{5}$ Age is also a common risk factor for developing COPD, but should not be overestimated. For example, COPD is often considered to be a disease of the later years, but estimates suggest that $50 \%$ of those with COPD are now younger than 65 years of age. ${ }^{120}$

The cause-effect diagram (Figure 2) shows the four ways that comorbidities may complicate COPD. Even if this eyecatching presentation tends to oversimplify the underlying interactions involved, the predominant cause-effect relationships are summarized. Lung cancer and COPD may share certain risk factors, like age, smoking, or genetic predisposition, but bronchial and systemic inflammation due to COPD may also contribute to carcinogenesis, swifting cancer to dependent comorbidity. ${ }^{121,122}$ The same is evident in several cardiovascular diseases, which also share common risk factors and seem to have a bidirectional inflammatory link with COPD that impairs outcomes for both diseases. ${ }^{123,124}$ Type 2 diabetes has been considered as a coincidental comorbidity, but evidence is accumulating in favor of considering diabetes and metabolic syndrome as dependent comorbidities. ${ }^{125}$

Systemic inflammation is the key for linking COPD and most of its dependent comorbidities. ${ }^{19,126}$ Without overlooking other pathways, like hypoxia and oxidative stress, the mainstream approach is that a variety of inflammatory mediators, including interferon- $\gamma$, interleukin-1, C-reactive protein, tumor necrosis factor- $\alpha$, interleukin- 6 , interleukin- 8 , surfactant protein D, fibrinogen, and amyloid protein, from the peripheral airways enter circulation and affect multiple distal organs. ${ }^{24,126,127}$ The opposite route is also evident, with inflammatory mediators produced in other organs, due to chronic conditions like heart failure or coronary disease, which may contribute to the pathogenesis of COPD structural abnormalities. Some researchers go as far as to propose that COPD is just a manifestation of a systemic inflammatory syndrome. ${ }^{71}$

COPD medications may also contribute to the development or worsening of certain comorbidities. ${ }^{88}$ Bronchodilators are suspected of causing tachyarrhythmias and tremors, but recent randomized clinical trials of long-acting $\beta$-agonists suggest that these effects probably do not increase cardiovascular mortality. ${ }^{128,129}$ Inhaled anticholinergics can affect intraocular pressure and bladder function and might have cardiovascular effects. ${ }^{130,131}$ Inhaled corticosteroids may increase the risk for cataracts, skin bruising, osteoporosis, and pneumonia. ${ }^{128}$ Systemic corticosteroids, often overprescribed in COPD patients, could contribute to diabetes, hypertension, osteoporosis, muscle dysfunction, and adrenal insufficiency. ${ }^{88}$ On the other hand, heart, liver, and kidney comorbidities need to be taken into account in terms of pharmacokinetic changes and pharmacodynamic modifications, which may lead to unfavorable side effects with suboptimal treatment. ${ }^{4,132}$

\section{Burden on health care costs}

COPD remains a major health issue with a significant economic impact. ${ }^{133}$ The prevalence of COPD is rising in developing and developed countries, resulting in increased

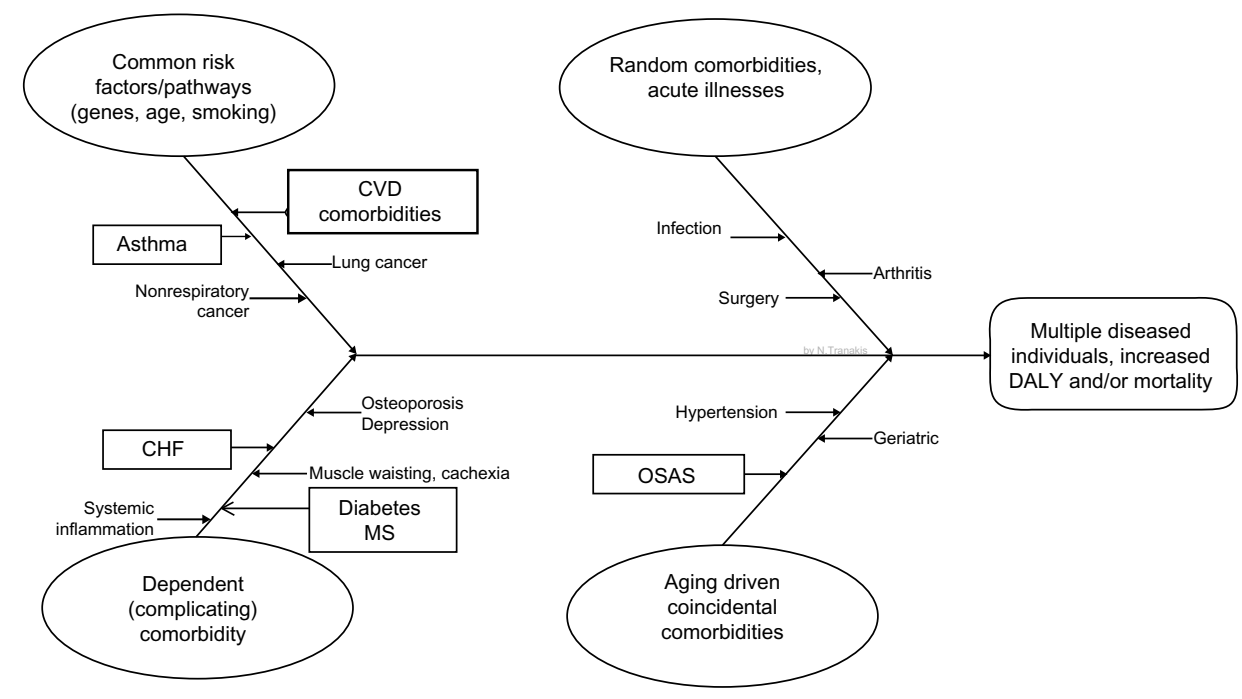

Figure 2 Cause-effect diagram shows the four different ways in which other abnormalities may be linked with COPD, presented in the same individual, the so-called multidiseased COPD patient, and leading in increase morbidity and mortality.

Abbreviations: CVD, cardiovascular disease; CHF, congestive heart failure; MS, metabolic syndrome; OSAS, obstructive sleep apnea syndrome; DALY, disability-adjusted life years; MS, Metabolic Syndrome; COPD, Chronic Obstructive Pulmonary Disease. 
direct and indirect costs of COPD to health care systems worldwide.

In the USA, direct costs have escalated from 18 billion dollars in 2002 to 29.5 billion in 2010, the largest part consisting of hospital expenses, ${ }^{134}$ whereas indirect costs accounted for $27 \%-61 \%$ of total costs, with the higher estimates produced by studies of working age populations. ${ }^{135,136}$ Average lifetime earnings losses for COPD patients retiring early have been estimated to be $\$ 316,000$ per individual. ${ }^{120}$ In Europe, the total annual cost of COPD is estimated at $€ 38.7$ billion. $^{137}$

The total annual direct costs of COPD expenditure are directly associated with the number of comorbidities, ${ }^{138}$ not the severity of airflow obstruction or health-related quality of life indices. ${ }^{139}$ Comorbidities, after age and chronic symptoms, are the factors most predictive of future health care costs. ${ }^{140}$ COPD patients with comorbidities have increased risk $^{66}$ and significantly higher mean costs for hospital admissions. ${ }^{141}$ Hospitalizations are the greatest contributor to total COPD costs, and account for up to $87 \%$ of total COPDrelated costs. ${ }^{142}$ Exacerbations are the leading but not the only cause of hospital admissions, and account for between $40 \%$ and $75 \%$ of the total health care cost of COPD, ${ }^{143,144}$ despite treatment with maintenance medications. ${ }^{133}$ Elevated costs in comorbid COPD patients are not only associated with hospitalizations: COPD patients use approximately $50 \%$ more cardiovascular agents than age-matched and sexmatched controls, and almost twice as many antibiotics, analgesics, and psychotherapeutic medications. ${ }^{138}$

COPD patients with multiple comorbidities make use of a disproportionately large percentage of the total overall health care expenditure on COPD. ${ }^{142,145}$ The median cost of COPD patients with multiple comorbidities has been found to be 4.7 times higher compared with comorbidity-free COPD patients. ${ }^{139}$ At the same time, compared with non-COPD controls, COPD patients consume 3.4 times more health care resources. ${ }^{139}$

It is obvious that holistic medical interventions are urgently needed for COPD management in order to decrease direct and indirect costs. These interventions must aim to reduce exacerbations of the disease and should emphasize personalized therapy according to different COPD phenotypes.

\section{Multimorbidities and outcomes}

Comorbidities seem to be present in the majority of COPD patients. Studies show that up to $94 \%$ of COPD patients have at least one comorbid disease and up to $46 \%$ have three or more. ${ }^{146}$ Even after correcting outcomes for age, sex, and smoking history, patients with COPD and comorbidities tend to have worse health status and functional impairment. ${ }^{30,147}$ The presence of three or more comorbidities is a better predictor of impaired health status than any other demographic or clinical variable. ${ }^{148}$ In mild-to-moderate COPD, lung cancer and cardiovascular comorbidities are the main causes of death and account for up to two thirds of all deaths in these patients, while respiratory failure only becomes predominant in advanced COPD. ${ }^{25-27}$

The use of health status questionnaires cannot always identify the presence of COPD comorbidities and the risk they pose on affecting outcomes. ${ }^{149}$ Attempts have been made to measure the relevant effect of multiple concomitant COPD comorbidities on outcomes, especially mortality, using several indexes or scales, which are not always designed exclusively for COPD patients. In these scales, each comorbidity is addressed separately. ${ }^{150}$ These include the Charlson Comorbidity Index, the Cumulative Illness Rating Scale, the Index of Coexisting Disease, and the Kaplan Index. ${ }^{10,151}$

The COTE index (a COPD-specific comorbidity test) identified 12 comorbidities that predicted death in COPD patients and is suggested as a complementary tool to the BODE (BMI, Obstruction, Dyspnea, Exercise) index. ${ }^{10}$ The COMCOLD (COMorbidities in Chronic Obstructive Lung Disease) index addresses the combined effect of COPD comorbidities on mortality and health-related quality of life. ${ }^{152}$ The use in clinical practice of multiple comorbidity indexes is a powerful tool for better stratifying COPD patients according to their risk for unfavorable outcomes and identifying high-risk patients that need attention paid to tailor-made treatment.

\section{Treatment and management}

The cornerstone of management for COPD and comorbidities is guideline-based treatment. The aim of this review is to focus on highlighting important key issues that complicate management of COPD in patients with comorbidities, in order to provide practical guidance for the pulmonary specialist physician in clinical practice. For this reason, we will not repeat in detail what is already established in the guidelines published for each disease.

The management and treatment of COPD is usually based on GOLD guidelines. ${ }^{5}$ Appropriate treatment (pharmacological and nonpharmacological) can reduce COPD symptoms, reduce the frequency and severity of exacerbations, and improve health status and exercise tolerance. 
The main pharmacological regimens are: $\beta_{2}$-agonists, anticholinergics (short-acting and long-acting, SABALABA), anticholinergics (short-acting and long-acting, SAMA-LAMA), combination short-acting $\beta_{2}$-agonists plus an anticholinergic in one inhaler, combination long-acting $\beta_{2}$-agonists plus an anticholinergic in one inhaler, methylxanthines, inhaled corticosteroids, combination long-acting $\beta_{2}$-agonists plus corticosteroids in one inhaler, systemic corticosteroids, and phosphodiesterase-4 inhibitors.

LABA have been associated with increased mortality and hospitalization in patients with heart failure and an increased risk of incident heart failure. ${ }^{153}$ Tiotropium, on the other hand, has been associated with a reduction in the risk of all-cause mortality, cardiovascular mortality, and cardiovascular events. ${ }^{154}$ Even if few long-term studies have measured changes in bone mineral density, inhaled steroid use for at least 3 years has not been associated with worsening major clinical features of osteoporosis. ${ }^{155}$ On the other hand, oral corticosteroids can potentially worsen coexistent heart failure, and are associated with an increased risk of arrhythmias. ${ }^{156}$ If used in COPD, close monitoring for hypertension, diabetes, and osteoporosis is recommended, as they have potentially harmful adverse effects. ${ }^{157}$ GOLD guidelines recommend a limited dosage. ${ }^{5}$ Theophylline is also correlated with increased risk for arrhythmias and atrial fibrillation. ${ }^{158}$ Each pharmacological treatment regimen needs to be patient-specific, and guided by severity of symptoms, risk of exacerbations, drug availability, and the patient's response. To date, none of the existing COPD medications have been shown conclusively to modify the long-term decline in lung function.

Patients with asthma and COPD seem to benefit from the use of combinations containing drugs with complementary pharmacological actions. The treatment of patients with asthma or COPD has also led to the discovery and development of drugs having two different primary pharmacological actions in the same molecule, which are now called "bifunctional drugs". 159

The joint project recently published by the science committees of GOLD and GINA ${ }^{20}$ confirms that initial treatment should be selected to ensure that patients with features of asthma receive adequate controller therapy including inhaled corticosteroids but not long-acting bronchodilators alone (as monotherapy), and patients with COPD receive appropriate symptomatic treatment with bronchodilators or combination therapy, but not inhaled corticosteroids alone (as monotherapy).

There is little specific guideline guidance for administering cardiovascular regimens to patients with comorbid
COPD. ${ }^{4}$ As a result, $\beta$-blockers are frequently underused in patients with COPD. ${ }^{11}$ Awareness is needed for patients with congestive heart failure and COPD not to be denied $\beta$-blocker treatment. ${ }^{160}$ Cardioselective $\beta$-blockers improve the prognosis without impairing lung function. Caution is needed because cardioselectivity decreases as the dosage escalates. ${ }^{161,162}$ However, even older nonselective $\beta$-blockers are well tolerated in most COPD patients. ${ }^{4}$ Patients with coronary heart disease should also not be denied the protective effects of $\beta$-blockers. ${ }^{163}$ GOLD guidelines recommend the use of the general coronary disease guidelines, and especially note the use of selective $\beta_{1}$-blockers even in patients with severe COPD. ${ }^{2,5}$ The use of angiotensin-converting enzyme (ACE) inhibitors by smokers may protect against a rapid decline in lung function and progression to COPD. ${ }^{164} \mathrm{Chronic}$ lowering of ACE improves pulmonary inflammation, respiratory muscle function, and peripheral use of oxygen. ${ }^{165} \mathrm{ACE}$ inhibitors and statins are associated in retrospective studies with reduced cardiovascular mortality, lower respiratory morbidity/mortality, and lower lung cancer risk. ${ }^{11}$ Statins though should be used with caution because they may worsen myopathy and elevate liver enzymes. All medications that metabolize through the cytochrome P450 system can be affected by administration of a statin. ${ }^{166}$

Treatment of OSAS largely does not differ between patients with COPD and those without. Treatment of COPD patients with OSAS is based on the treatment of constituent diseases (for COPD bronchodilators, inhaled steroids when indicated, rehabilitation, nutrition, domiciliary oxygen when indicated, and for OSA weight loss and application of continuous positive airway pressure [CPAP]). ${ }^{107,108}$ The goal of treatment is to maintain adequate oxygenation at all times and to prevent sleep-disordered breathing. CPAP remains the accepted standard treatment for OSA, but CPAP alone may not fully correct hypoxemia, so supplemental oxygen may be required.

The large prevalence of concealed and overt chronic kidney failure in COPD patients, especially the elderly, indicates that awareness is needed for monitoring and addressing adverse effects caused mainly by hydrosoluble drugs, which are cleared by the kidney. Special attention is warranted for drugs like thiazides or digoxin, used in the treatment of cardiovascular comorbidities, but also antibiotics commonly used in acute exacerbations of COPD. ${ }^{117,167}$

The nonpharmacological treatment of COPD patients includes smoking cessation (counseling plus pharmacotherapy), influenza and pneumococcal vaccination, and pulmonary rehabilitation. Pulmonary rehabilitation, 
a nonpharmacological intervention, has the potential to affect a number of comorbidities alongside COPD, through exercise training, emphasis on self-management and behavioral change, and psychological support. ${ }^{37}$ Physical activity and regular exercise are proven to be beneficial for multiple comorbidities, including cardiovascular disease, diabetes, or musculoskeletal diseases. ${ }^{168-171}$ Smoking cessation is the most cost-effective method for slowing COPD progression, and has proven beneficial effects on the outcomes of most comorbidities, for which smoking is a major risk factor. ${ }^{24}$ Despite the abundance of data on smoking, only a small percentage of smokers in the USA have received any kind of smoking cessation intervention. ${ }^{172,173}$ Similarly, the percentage of the population that currently receives influenza vaccination is also low. ${ }^{172}$

The harmful and beneficial effects of pharmacological and nonpharmacological treatments underscore the paramount importance of a multidisciplinary approach in order to improve outcomes. Management of COPD needs a systemic holistic approach that does not neglect the nonrespiratory component of treatment.

Given the potential complications of treatment and the interactions between comorbid diseases and COPD, some researchers have started to advocate for an integrated care approach to the management of patients with COPD. There is a need for a chronic care model approach to the management of COPD, including automatic screening for common comorbidities.

In order to truly build such a chronic care model, future research has to be moved in certain directions: including patients with comorbid conditions in clinical trials with appropriate analytic strategies to understand the heterogeneity of the

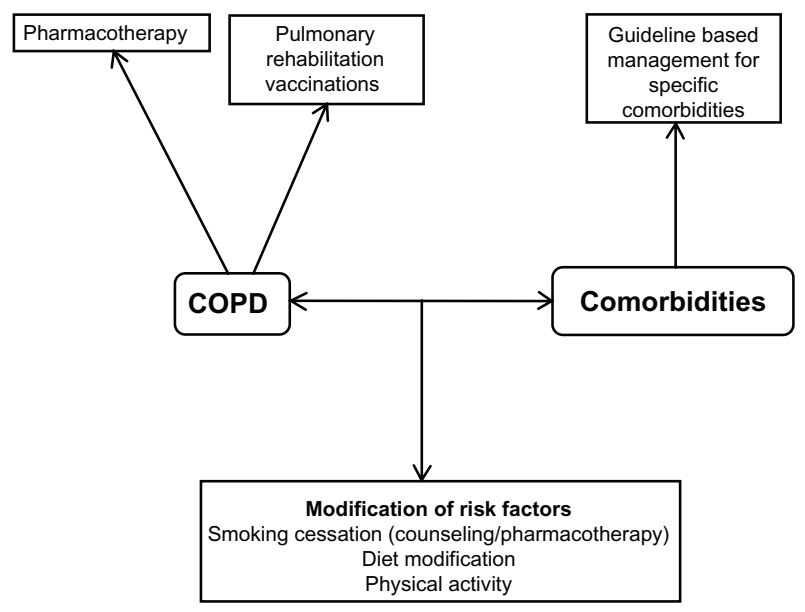

Figure 3 A holistic approach to medical intervention. Abbreviation: COPD, chronic obstructive pulmonary disease. treatment effect; investigating the development of a method for assessing and scoring comorbidities so that we can provide accurate prognostic information for patients as well as treat in a robust effective manner; evaluating current treatment regimens in patients with different patterns of comorbid conditions; and continuing to study possible pathophysiological connections between COPD and comorbidities.

\section{Conclusion}

Management and medical intervention in COPD patients with comorbidities needs a holistic approach (Figure 3 ), that is not clearly established in guidelines worldwide regarding the management of major chronic diseases. This holistic approach includes COPD management based on pharmacological and nonpharmacological treatment, guideline-based management for specific comorbidities, and modification of the risk factors for COPD and comorbidities.

All health care specialists in COPD management need to work together with professionals specialized in the management of other major chronic diseases in order to provide a multidisciplinary treatment strategy for COPD patients with comorbidities. More studies are needed to clarify and establish a holistic approach to medical intervention in comorbid COPD patients.

\section{Disclosure}

The authors report no conflicts of interest in this work.

\section{References}

1. Rabe KF, Hurd S, Anzueto A, et al. Global strategy for the diagnosis, management and prevention of chronic obstructive pulmonary disease: GOLD executive summary. Am J Respir Crit Care Med. 2007;176(6):532-555.

2. World Health Organization. Chronic obstructive pulmonary disease (COPD). 2011. Available from: http://www.who.int/respiratory/copd http://www.who.int/respiratory/copd. Accessed September 25, 2014.

3. Chatila WM, Thomashow BM, Minai OA, Criner GJ, Make BJ. Comorbidities in chronic obstructive pulmonary disease. Proc Am Thorac Soc. 2008;5(4):549-555.

4. Tsiligianni IG, Kosmas E, Van der Molen T, Tzanakis N. Managing comorbidity in COPD: a difficult task. Curr Drug Targets. 2013;14(2): 158-176.

5. Global Initiative for Chronic Obstructive Lung Disease. Global strategy for the diagnosis, management and prevention of chronic obstructive pulmonary disease. Revised 2014. Available from: http://www. goldcopd.org/guidelines-global-strategy-for-diagnosis-management. html. Accessed September 14, 2014.

6. Koskela J, Kilpeläinen M, Kupiainen H, et al. Co-morbidities are the key nominators of the health related quality of life in mild and moderate COPD. BMC Pulm Med. 2014;14(1):102.

7. Valderas JM, Starfield B, Sibbald B, Salisbury C, Roland M. Defining comorbidity: implications for understanding health and health services. Ann Fam Med. 2009;7(4):357-363.

8. Bower P, Macdonald W, Harkness E, et al. Multiborbidity, service organization and clinical decision making in primary care: a qualitative study. Fam Pract. 2011;28(5):579-587. 
9. MacNee W. Systemic inflammatory biomarkers and co-morbidities of chronic obstructive disease. Ann Med. 2013;45(3):291-300.

10. Divo M, Cote C, de Torres JP, et al. Comorbidities and risk of mortality in patients with chronic obstructive pulmonary disease. Am J Respir Crit Care Med. 2012;186(2):155-161.

11. Corsonello A, Antonelli Incalzi R, Pistelli R, Pedone C, Bustacchini S, Lattanzio F. Comorbidities of chronic obstructive pulmonary disease. Curr Opin Pulm Med. 2011;17 Suppl 1:S21-S28.

12. Soriano JB, Visick GT, Muellerova H, Payvandi N, Hansell AL. Patterns of comorbidities in newly diagnosed COPD and asthma in primary care. Chest. 2005;128(4):2099-2107.

13. Fu JJ, McDonald VM, Gibson PG, Simpson JL. Systemic inflammation in older adults with asthma-COPD overlap syndrome. Allergy Asthma Immunol Res. 2014;6(4):316-324.

14. Marsh SE, Travers J, Weatherall M, et al. Proportional classifications of COPD phenotypes. Thorax. 2008;63(9):761-767.

15. Gibson PG, Simpson JL. The overlap syndrome of asthma and COPD: what are its features and how important is it? Thorax. 2009;64(8): 728-775.

16. Hardin M, Silverman EK, Barr RG, et al; COPDGene Investigators. The clinical features of the overlap between COPD and asthma. Respir Res. 2011;12:127.

17. Tashkin DP, Celli B, Senn S, et al. A 4-year trial of tiotropium in chronic obstructive pulmonary disease. $N$ Engl J Med. 2008;359(15): 1543-1554.

18. Tashkin DP, Celli B, Decramer M, et al. Bronchodilator responsiveness in patients with COPD. Eur Respir J. 2008;31(4):742-750.

19. Hurst JR, Vestbo J, Anzueto A, et al. Susceptibility to exacerbation in chronic obstructive pulmonary disease. $N$ Engl J Med. 2010;363(12): $1128-1138$.

20. Global Initiative for Asthma. Diagnosis of diseases of chronic airflow limitation: asthma COPD and asthma-COPD overlap syndrome (ACOS). Available from: http://www.ginasthma.org/local/uploads/files/ AsthmaCOPDOverlap.pdf. Accessed September 14, 2014.

21. Kiri VA, Soriano J, Visick G, Fabbri L. Recent trends in lung cancer and its association with COPD: an analysis using the UK GP Research Database. Prim Care Respir J. 2010;19(1):57-61.

22. Tammemagi CM, Neslund-Dudas C, Simoff M, Kvale P. Impact of comorbidity on lung cancer survival. Int J Cancer. 2003;103(6):792-802.

23. Loganathan RS, Stover DE, Shi W, Venkatraman E. Prevalence of COPD in women compared to men around the time of diagnosis of primary lung cancer. Chest. 2006;129(5):1305-1312.

24. Young RP, Hopkins RJ, Christmas T, Black PN, Metcalf P, Gamble GD. COPD prevalence is increased in lung cancer, independent of age, sex and smoking history. Eur Respir J. 2009;34(2):380-386.

25. Cavaillès A, Brinchault-Rabin G, Dixmier A, et al. Comorbidities of COPD. Eur Respir Rev. 2013;22(130):454-475.

26. Sin DD, Anthonisen NR, Soriano JB, Agusti AG. Mortality in COPD: the role of comorbidities. Eur Respir J. 2006;28(6):1245-1257.

27. Anthonisen NR, Skeans MA, Wise RA, Manfreda J, Kanner RE, Connett JE; Lung Health Study Research Group. The effects of a smoking cessation intervention on 14.5-year mortality: a randomized clinical trial. Ann Intern Med. 2005;142(4):233-239.

28. Garcia-Aymerich J, Farrero E, Felez MA, et al. Risk factors of readmission to hospital for a COPD exacerbation: a prospective study. Thorax. 2003;58(2):100-105.

29. Washko GR, Hunninghake GM, Fernanzez IE, et al; COPDGene Investigators. Lung volumes and emphysema in smokers with interstitial lung abnormalities. N Engl J Med. 2011;364(10):897-906.

30. Schonhofer B, Wenzel M, Geibel M, Köhler D. Blood transfusion and lung function in chronically anemic patients with severe chronic obstructive pulmonary disease. Crit Care Med. 1998;26(11): 1824-1828.

31. Miller J, Edwards LD, Agustí A, et al; Evaluation of COPD Longitudinally to Identify Predictive Surrogate Endpoints (ECLIPSE) Investigators. Comorbidity, systemic inflammation and outcomes in the ECLIPSE cohort. Respir Med. 2013;107(9):1376-1384.
32. Eriksson B, Lindberg A, Muellerova H, Rönmark E, Lundbäck B Association of heart diseases with COPD and restrictive lung function - results from a population survey. Respir Med. 2013;107(1): 98-106.

33. Le Jemtel TH, Padeletti M, Jelic S. Diagnostic and therapeutic challenges in patients with coexistent chronic obstructive pulmonary disease and chronic heart failure. Am J Coll Cardiol. 2007;49(2):171-180.

34. Rutten FH, Cramer MJ, Lammers JW, Grobbee DE, Hoes AW Heart failure and chronic obstructive pulmonary disease: an ignored combination? Eur J Heart Fail. 2006;8(7):707-711.

35. Sidney S, Sorel M, Quesenberry CP Jr, DeLuise C, Lanes S, Eisner MD. COPD and incident cardiovascular disease. Hospitalizations and mortality: Kaiser Permanente Medical Care Program. Chest. 2005;128(4):2068-2075.

36. Garcia-Rodriguez LA, Wallander MA, Martin-Merino E, Johansson S. Heart failure, myocardial infarction, lung cancer and death in COPD patients: a UK primary care study. Respir Med. 2010;104(11): 1691-1699.

37. Mascarenhas J, Lourenco P, Lopes R, Azevedo A, Bettencourt P. Chronic obstructive pulmonary disease in heart failure. Prevalence, therapeutic and prognostic implications. Am Heart J. 2008;155(3):521-525.

38. Franssen FM, Rochester CL. Comorbidities in patients with COPD and pulmonary rehabilitation: do they matter? Eur Respir Rev. 2014;23(131):131-141.

39. Rutten FH, Vonken EJ, Cramer MJ, et al. Cardiovascular magnetic resonance imaging to identify left-sided chronic heart failure in stable patients with chronic obstructive pulmonary disease. Am Heart $J$. 2008;156(3):506-512.

40. Sin DD, Man SF. Chronic obstructive pulmonary disease as a risk factor for cardiovascular morbidity and mortality. Proc Am Thorac Soc. 2005;2(1):8-11.

41. Brekke PH, Omland T, Smith P, Søyseth V. Underdiagnosis of myocardial infarction in COPD - Cardiac Infarction Injury Score (CIIS) in patients hospitalised for COPD exacerbation. Respir Med. 2008;102(9): $1243-1247$

42. Sin DD, Man SF. Why are patients with chronic obstructive pulmonary disease at increased risk of cardiovascular diseases? The potential role of systemic inflammation in chronic obstructive pulmonary disease. Circulation. 2003;107(11):1514-1519.

43. Huang B, Yang Y, Zhu J, et al. Clinical characteristics and prognostic significance of chronic obstructive pulmonary disease in patients with atrial fibrillation: results from a multicenter atrial fibrillation registry study. J Am Med Dir Assoc. 2014;15(8):576-581.

44. Konecny T, Park JY, Somers KR, et al. Relation of chronic obstructive pulmonary disease to atrial and ventricular arrhythmias. Am J Cardiol. 2014;114(2):272-277.

45. Li J, Agarwal SK, Alonso A, et al. Airflow obstruction, lung function, and incidence of atrial fibrillation: the Atherosclerosis Risk in Communities (ARIC) study. Circulation. 2014;129(9):971-980.

46. Zoni-Berisso M, Lercari F, Carazza T, Domenicucci S. Epidemiology of atrial fibrillation: European perspective. Clin Epidemiol. 2014;6: 213-220.

47. Gulsvik A, Hansteen V, Sivertssen E. Cardiac arrhythmias in patients with serious pulmonary diseases. Sand J Respir Dis. 1978;59(3): 154-159.

48. Hayashi T, Fukamizu S, Hojo R, et al. Prevalence and electrophysiological characteristics of typical atrial flutter in patients with atrial fibrillation and chronic obstructive pulmonary disease. Europace. 2013;15(12):1777-1783.

49. Chaouat A, Naeije R, Weitzenblum E. Pulmonary hypertension in COPD. Eur Respir J. 2008;32(5):1371-1385.

50. Chaouat A, Bugnet AS, Kadaoui N, et al. Severe pulmonary hypertension and chronic obstructive pulmonary disease. Am J Respir Crit Care Med. 2005;172(2):189-194.

51. Jyothula S, Safdar Z. Update on pulmonary hypertension complicating chronic obstructive pulmonary disease. Int J Chron Obstruct Pulmon Dis. 2009;4:351-363. 
52. Weitzenblum E, Sautegeau A, Ehrhart M, Mammosser M, Pelletier A. Long-term oxygen therapy can reverse the progression of pulmonary hypertension in patients with chronic obstructive pulmonary disease. Am Rev Respir Dis. 1985;131(4):493-498.

53. Tillie-Leblond I, Marquette CH, Perez T, et al. Pulmonary embolism in patients with unexplained exacerbation of chronic obstructive pulmonary disease: prevalence and risk factors. Ann Intern Med. 2006;144(6): 390-396.

54. Gunen H, Gulbas G, In E, Yetkin O, Hacievliyagil SS. Venous thromboemboli and exacerbations of COPD. Eur Respir J. 2010;35(6): 1243-1248.

55. Chen WJ, Lin CC, Lin CY, et al. Pulmonary embolism in chronic obstructive pulmonary disease: a population-based cohort study. COPD. 2014;11(4):438-443.

56. Peinado VI, Barbera JA, Ramirez J, et al. Endothelial dysfunction in pulmonary arteries of patients with mild COPD. Am J Physiol. 1998; 274(6 Pt 1):908-913.

57. Barr RG, Mesia-Vela S, Austin JH, et al. Impaired flow-mediated dilation is associated with low pulmonary function and emphysema in ex-smokers: the Emphysema and Cancer Action Project (EMCAP) Study. Am J Respir Crit Care Med. 2007;176(12):1200-1207.

58. Sabit R, Thomas P, Shale DJ, Collins P, Linnane SJ. The effects of hypoxia on markers of coagulation and systemic inflammation in patients with COPD. Chest. 2010;138(1):47-51.

59. Undas A, Kaczmarek P, Sladek K, et al. Fibrin clot properties are altered in patients with chronic obstructive pulmonary disease. Beneficial effects of simvastatin treatment. Thromb Haemost. 2009;102(6): 1176-1182.

60. Doehner W, Haeusler KG, Endres M, Anker SD, MacNee W, Lainscak M. Neurological and endocrinological disorders: orphans in chronic obstructive pulmonary disease. Respir Med. 2011;105 Suppl 1: $12-19$

61. Vaidyula VR, Criner GJ, Grabianowski C, Rao AK. Circulating tissue factor procoagulant activity is elevated in stable moderate to severe chronic obstructive pulmonary disease. Thromb Res. 2009;124(3): 259-261.

62. Hozawa A, Billings JL, Shahar E, Ohira T, Rosamond WD, Folsom AR. Lung function and ischemic stroke incidence: the Atherosclerosis Risk in Communities study. Chest. 2006;130(6):1642-1649.

63. Finkelstein J, Cha E, Scharf SM. Chronic obstructive pulmonary disease as an independent risk factor for cardiovascular morbidity. Int J Chron Obstruct Pulmon Dis. 2009;4:337-349.

64. McGarvey LP, John M, Anderson JA, Zvarich M, Wise RA; TORCH Clinical Endpoint Committee. Ascertainment of cause-specific mortality in COPD: operations of the TORCH Clinical Endpoint Committee. Thorax. 2007;62(5):411-415.

65. Crisafulli E, Costi S, Luppi F, et al. Role of comorbidities in a cohort of patients with COPD undergoing pulmonary rehabilitation. Thorax. 2008;63(6):487-492.

66. Cazzola M, Bettoncelli G, Sessa E, Cricelli C, Biscione G. Prevalence of comorbidities in patients with chronic obstructive pulmonary disease. Respiration. 2010;80(2):112-119.

67. Mannino DM, Thorn D, Swensen A, Holguin F. Prevalence and outcomes of diabetes, hypertension and cardiovascular disease in COPD. Eur Respir J. 2008;32(4):962-969.

68. Song Y, Klevak A, Manson JE, Buring JE, Liu S. Asthma, chronic obstructive pulmonary disease, and type 2 diabetes in the Women's Health Study. Diabetes Res Clin Pract. 2010;90(3): 365-371.

69. Ehrlich SF, Quesenberry CP Jr, Van Den Eeden SK, Shan J, Ferrara A. Patients diagnosed with diabetes are at increased risk for asthma, chronic obstructive pulmonary disease, pulmonary fibrosis, and pneumonia but not lung cancer. Diabetes Care. 2010;33(1):55-60.

70. Feary JR, Rodrigues LC, Smith CJ, Hubbard RB, Gibson J. Prevalence of major comorbidities in subjects with COPD and incidence of myocardial infarction and stroke: a comprehensive analysis using data from primary care. Thorax. 2010;65(11):956-962.
71. Tkacova R. Systemic inflammation in chronic obstructive pulmonary disease: may adipose tissue play a role? Review of the literature and future perspectives. Mediators Inflamm. 2010;2010:585989.

72. Fabbri LM, Luppi F, Beghé B, Rabe KF. Complex chronic comorbidities of COPD. Eur Respir J. 2008;31(1):204-212.

73. Emerging Risk Factors Collaboration; Seshasai SR, Kaptoge S, Thompson A, et al. Diabetes mellitus, fasting glucose, and risk of cause-specific death. $N$ Engl J Med. 2011;364(9):829-841.

74. Baker EH, Janaway CH, Philips BJ, et al. Hyperglycaemia is associated with poor outcomes in patients admitted to hospital with acute exacerbations of chronic obstructive pulmonary disease. Thorax. 2006;61(4): 284-289.

75. Parappil A, Depczynski B, Collett P, Marks GB. Effect of comorbid diabetes on length of stay and risk of death in patients admitted with acute exacerbations of COPD. Respirology. 2010;15(6):918-922.

76. Watanabe R, Tanaka T, Aita K, et al. Osteoporosis is highly prevalent in Japanese males with chronic obstructive pulmonary disease and is associated with deteriorated pulmonary function. J Bone Miner Metab. July 5, 2014. [Epub ahead of print.]

77. Ferguson GT, Calverley PM, Anderson JA, et al. Prevalence and progression of osteoporosis in patients with COPD: results from the Towards a Revolution in COPD Health Study. Chest. 2009;136(6):1456-1465.

78. Graat-Verboom L, Wouters EF, Smeenk FW, van den Borne BE, Lunde R, Spruit MA. Current status of research on osteoporosis in COPD: a systematic review. Eur Respir J. 2009;34(1):209-218.

79. Janssens W, Bouillon R, Claes B, et al. Vitamin D deficiency is highly prevalent in COPD and correlates with variants in the vitamin D-binding gene. Thorax. 2010;65(3):215-220.

80. Maggi S, Siviero P, Gonnelli S, et al. EOLO Study Group. Osteoporosis risk in patients with chronic obstructive pulmonary disease: the EOLO study. J Clin Densitom. 2009;12(3):345-352.

81. Scanlon PD, Connett JE, Wise RA, et al. Lung Health Study Research Group. Loss of bone density with inhaled triamcinolone in Lung Health Study II. Am J Respir Crit Care Med. 2004;170(12):1302-1309.

82. Agusti A, Soriano JB. COPD as a systemic disease. COPD. 2008;5(2): $133-138$.

83. Rutten EP, Breyer MK, Spruit MA, et al. Abdominal fat mass contributes to the systemic inflammation in chronic obstructive pulmonary disease. Clin Nutr. 2010;29(6):756-760.

84. Seymour JM, Spruit MA, Hopkinson NS, et al. The prevalence of quadriceps weakness in COPD and the relationship with disease severity. Eur Respir J. 2010;36(1):81-88.

85. Cielen N, Maes K, Gayan-Ramirez G. Musculoskeletal disorders in chronic obstructive pulmonary disease. Biomed Res Int. 2014; 2014:965764.

86. Decramer M, Janssens W, Miravitlles M. Chronic obstructive pulmonary disease. Lancet. 2012;379(9823):1341-1351.

87. Engelen MP, Schols AM, Does JD, Wouters EF. Skeletal muscle weakness is associated with wasting of extremity fat-free mass but not with airflow obstruction in patients with chronic obstructive pulmonary disease. Am J Clin Nutr. 2000;71(3):733-738.

88. [No authors listed]. Skeletal muscle dysfunction in chronic obstructive pulmonary disease. A statement of the American Thoracic Society and European Respiratory Society. Am J Respir Crit Care Med. 1999; 159(4 Pt 2):1-40.

89. Kunik ME, Roundy K, Veazey C, et al. Surprisingly high prevalence of anxiety and depression in chronic breathing disorders. Chest. 2005; 127(4):1205-1211.

90. Barr RG, Celli BR, Mannino DM, et al. Comorbidities, patient knowledge, and disease management in a national sample of patients with COPD. Am J Med. 2009;122(4):348-355.

91. Norwood R. Prevalence and impact of depression in chronic obstructive disease patients. Curr Opin Pulm Med. 2006;12(2):113-117.

92. Pooler A, Beech R. Examining the relationship between anxiety and depression and exacerbations of COPD which result in hospital admission: a systematic review. Int J Chron Obstruct Pulmon Dis. 2014;9:315-330. 
93. Spitzer C, Gläser S, Grabe HJ, et al. Mental health problems, obstructive lung disease and lung function: findings from the general population. J Psychosom Res. 2011;71(3):174-179.

94. Regvat J, Zmitek A, Vegnuti M, Košnik M, Šuškovič S. Anxiety and depression during hospital treatment of exacerbation of chronic obstructive pulmonary disease. J Int Med Res. 2011;39(3):1028-1038.

95. Abrams TE, Vaughan-Sarrazin M, Van der Weg MW. Acute exacerbations of chronic obstructive pulmonary disease and the effect of existing psychiatric comorbidity on subsequent mortality. Psychosomatics. 2011;52(5):441-449.

96. Laurin C, Lavoie KL, Bacon SL, et al. Sex differences in the prevalence of psychiatric disorders and psychological distress in patients with COPD. Chest. 2007;132(1):148-155.

97. Paz-Diaz H, Montes de Oca M, Lopez JM, Celli BR. Pulmonary rehabilitation improves depression, anxiety, dyspnea and health status in patients with COPD. Am J Phys Med Rehabil. 2007;86(1):30-36.

98. Schneider C, Jick SS, Bothner U, Meier CR. COPD and the risk of depression. Chest. 2010;137(2):341-347.

99. Al-shair K, Dockry R, Mallia-Milanes B, Kolsum U, Singh D, Vestbo J. Depression and its relationship with poor exercise capacity, BODE index and muscle wasting in COPD. Respir Med. 2009;103(10):1572-1579.

100. Omachi TA, Katz PP, Yelin EH, et al. Depression and health-related quality of life in chronic obstructive pulmonary disease. $\mathrm{Am} \mathrm{J} \mathrm{Med}$. 2009;112(8):778. e9-e15.

101. DiMatteo MR, Lepper HS, Croghan TW. Depression is a risk factor for noncompliance with medical treatment: meta-analysis of the effects of anxiety and depression on patient adherence. Arch Intern Med. 2000;160(14):2101-2107.

102. Xu W, Collet JP, Shapiro S, et al. Independent effect of depression and anxiety on chronic obstructive pulmonary disease exacerbations and hospitalizations. Am J Respir Crit Care Med. 2008;178(9):913-920.

103. Jennings JH, Digiovine B, Obeid D, Frank C. The association between depressive symptoms and acute exacerbations of COPD. Lung. 2009; 187(2):128-135.

104. Ng TP, Niti M, Tan WC, Cao Z, Ong KC, Eng P. Depressive symptoms and chronic obstructive pulmonary disease: effect on mortality, hospital readmission, symptom burden, functional status, and quality of life. Arch Intern Med. 2007;167(1):60-67.

105. Yohannes AM, Balwin RC, Connolly MJ. Prevalence of sub-threshold depression in elderly patients with chronic obstructive pulmonary disease. Int J Geriatr Psychiatry. 2003;18(5):412-616.

106. Qian J, Simoni-Wastila L, Langenberg P, et al. Effects of depression diagnosis and antidepressant treatment on mortality in Medicare beneficiaries with chronic obstructive pulmonary disease. J Am Geriatr Soc. 2013;61(5):754-761.

107. Krachman S, Minai OA, Scharf SM. Sleep abnormalities and treatment in emphysema. Proc Am Thorac Soc. 2008;5(4):536-542.

108. Machado MC, Vollmer WM, Togeiro SM, et al. CPAP and survival in moderate-to-severe obstructive sleep apnoea syndrome and hypoxaemic COPD. Eur Respir J. 2010;35(1):132-137.

109. Marin JM, Soriano JB, Carrizo SJ, Boldova A, Celli BR. Outcomes in patients with chronic obstructive pulmonary disease and obstructive sleep apnea: the overlap syndrome. Am J Respir Crit Care Med. 2010;182(3):325-331.

110. McNicholas WT. Chronic obstructive pulmonary disease and obstructive sleep apnea: overlaps in pathophysiology, systemic inflammation, and cardiovascular disease. Am J Respir Crit Care Med. 2009;180(8): 692-700.

111. Vestbo J, Hurd SS, Agustí AG, et al. Global strategy for the diagnosis, management, and prevention of chronic obstructive pulmonary disease: GOLD executive summary. Am J Respir Crit Care Med. 2013;187(4):347-365.

112. Terada K, Muro S, Sato S, et al. Impact of gastro-oesophageal reflux disease symptoms on COPD exacerbation. Thorax. 2008;63(11):951-955.

113. Kempainen RR, Savik K, Whelan TP, Dunitz JM, Herrington CS, Billings JL. High prevalence of proximal and distal gastroesophageal reflux disease in advanced COPD. Chest. 2007;131(6):1666-1671.
114. Mokhlesi B, Morris AL, Huang CF, Curcio AJ, Barrett TA, Kamp DW. Increased prevalence of gastroesophageal reflux symptoms in patients with COPD. Chest. 2001;119(4):1043-1048.

115. Rascon-Aguilar IE, Pamer M, Wludyka P, et al. Role of gastroesophageal reflux symptoms in exacerbations of COPD. Chest. 2006;130(4) 1096-1101.

116. Mapel DW, Marton JP. Prevalence of renal and hepatobiliary disease, laboratory abnormalities, and potentially toxic medication exposures among persons with COPD. Int J Chron Obstruct Pulmon Dis. 2013;8: 127-134.

117. Chen CY, Hsu TW, Mao SJ, et al. Abnormal renal resistive index in patients with mild-to-moderate chronic obstructive pulmonary disease. COPD. 2013;10(2):216-225.

118. Incalzi RA, Corsonello A, Pedone C, Battaglia S, Paglino G, Bellia V; Extrapulmonary Consequences of COPD in the Elderly Study Investigators. Chronic renal failure: a neglected comorbidity of COPD. Chest. 2010;137(4):831-837.

119. Gjerde B, Bakke PS, Ueland T, Hardie JA, Eagan TM. The prevalence of undiagnosed renal failure in a cohort of COPD patients in western Norway. Respir Med. 2012;106(3):361-366.

120. Barnes PJ. Chronic obstructive pulmonary disease: effects beyond the lungs. PLoS Med. 2010;7(3):e1000220.

121. Fletcher MJ, Upton J, Taylor-Fishwick J, et al. COPD uncovered: an international survey on the impact of chronic obstructive pulmonary disease [COPD] on a working age population. BMC Public Health. 2011;11:612.

122. Young RP, Whittington CF, Hopkins RJ, et al. Chromosome 4q31 locus in COPD is also associated with lung cancer. Eur Respir J. 2010;36(6):1375-1382.

123. Young RP, Hopkins RJ, Hay BA, Epton MJ, Black PN, Gamble GD. Lung cancer gene associated with COPD: triple whammy or possible confounding effect? Eur Respir J. 2008;32(5):1158-1164.

124. Hansson GK. Inflammation, atherosclerosis, and coronary artery disease. N Engl J Med. 2005;352(6):1685-1695.

125. Eickhoff P, Valipour A, Kiss D, et al. Determinants of systemic vascular function in patients with stable chronic obstructive pulmonary disease. Am J Respir Crit Care Med. 2008;178(12): 1211-1218.

126. Mirrakhimov AE. Chronic obstructive pulmonary disease and glucose metabolism: a bitter sweet symphony. Cardiovasc Diabetol. 2012;11:132

127. Barnes PJ, Celli BR. Systemic manifestations and comorbidities of COPD. Eur Respir J. 2009;33(5):1165-1185.

128. Fabbri LM, Rabe KF. From COPD to chronic systemic inflammatory syndrome? Lancet. 2007;370(9589):797-799.

129. Calverley PM, Anderson JA, Celli B, et al. Cardiovascular events in patients with COPD: TORCH study results. Thorax. 2010;65(8): 719-725.

130. Calverley PM, Anderson JA, Celli B, et al. Salmeterol and fluticasone propionate and survival in chronic obstructive pulmonary disease. N Engl J Med. 2007;356(8):775-789.

131. Wedzicha JA, Caverley PM, Seemungal TA, Hagan G, Ansari Z, Stockley RA; INSPIRE Investigators. The prevention of chronic obstructive pulmonary disease exacerbations by salmeterol/fluticasone propionate or tiotropium bromide. Am J Respir Crit Care Med. 2008; 177(1):19-26.

132. Barr RG, Bourbeau J, Camargo CA Jr, Ram FS. Inhaled tiotropium for stable chronic obstructive pulmonary disease: a meta-analysis. Thorax. 2006;61(10):854-862.

133. Valente S, Pasciuto G, Bernabei R, Corbo GM. Do we need different treatments for very elderly COPD patients? Respiration. 2010;80(5):357-368.

134. Pasquale MK, Sun SX, Song F, Hartnett HJ, Stemkowski SA. Impact of exacerbations on health care cost and resource utilization in chronic obstructive pulmonary disease patients with chronic bronchitis from a predominantly Medicare population. Int J Chron Obstruct Pulmon Dis. 2012;7:757-764. 
135. Ornek T, Tor M, Altin R, et al. Clinical factors affecting the direct cost of patients hospitalized with acute exacerbation of chronic obstructive pulmonary disease. Int J Med Sci. 2012;9(4):285-290.

136. Patel JG, Nagar SP, Dalal AA. Indirect costs in chronic obstructive pulmonary disease: a review of the economic burden on employers and individuals in the United States. Int J Chron Obstruct Pulmon Dis. 2014;9:289-300.

137. National Heart, Lung, and Blood Institute. Morbidity and Mortality 2009: Chart Book on Cardiovascular, Lung and Blood Diseases. Bethesda, MD, USA: National Institutes of Health; 2009.

138. Halpin DM, Miravitlles M. Chronic obstructive pulmonary disease: the disease and its burden to society. Proc Am Thorac Soc. 2006;3(7):619-623.

139. Mapel DW, Hurley JS, Frost FJ, Petersen HV, Picchi MA, Coultas DB. Health care utilization in chronic obstructive pulmonary disease. A case-control study in a health maintenance organization. Arch Intern Med. 2000;160(17):2653-2658.

140. Simon-Tuval T, Scharf SM, Maimon N, Bernhard-Scharf BJ, Reuveni H, TarasiukA. Determinants of elevated healthcare utilization in patients with COPD. Respir Res. 2011;12:7.

141. Mannino DM, Watt G, Hole D, et al. The natural history of chronic obstructive pulmonary disease. Eur Respir J. 2006;27(3): 627-643.

142. Doos L, Uttley J, Onyia I, Iqbal Z, Jones PW, Kadam UT. Mosaic segmentation, COPD and CHF multimorbidity and hospital admission costs: a clinical linkage study. J Public Health (Oxf). 2014;36(2): 317-324.

143. Darnell K, Dwivedi AK, Weng Z, Panos RJ. Disproportionate utilization of healthcare resources among veterans with COPD: a retrospective analysis of factors associated with COPD healthcare cost. Cost Eff Resour Alloc. 2013;11:13.

144. Hilleman D, Dewan N, Malesker M, Friedman M. Pharmacoeconomic evaluation of COPD. Chest. 2000;118(5):1278-1285.

145. Teo W, Tan WS, Chong W, et al. Economic burden of chronic obstructive pulmonary disease. Respirology. 2012;17(1):120-126.

146. SharafkhanehA, Petersen N, Yu HJ, DalalAA, Johnson ML, Hanania NA. Burden of COPD in a government health care system: a retrospective observational study using data from the US Veterans Affairs population. Int J Chron Obstruct Pulmon Dis. 2010;5:125-132.

147. Fumagalli G, Fabiani F, Forte S, et al. INDACO project: a pilot study on incidence of comorbidities in COPD patients referred to pneumology units. Multidiscip Respir Med. 2013;8(1):28.

148. Giardino ND, Curtis JL, Andrei AC, et al; NETT Research Group. Anxiety is associated with diminished exercise performance and quality of life in severe emphysema: a cross-sectional study. Respir Res. 2010;11:29.

149. van Manen JG, Bindels PJ, Dekker EW, et al. Added value of co-morbidity in predicting health-related quality of life in COPD patients. Respir Med. 2001;95(6):496-504.

150. Miyazaki M, Nakamura H, Chubachi S, et al; Keio COPD Comorbidity Research (K-CCR) Group. Analysis of comorbid factors that increase the COPD assessment test scores. Respir Res. 2014;15:13.

151. Hall SF. A user's guide to selecting a comorbidity index for clinical research. J Clin Epidemiol. 2006;59(8):849-855.

152. Charlson ME, Pompei P, Ales KL, MacKenzie CR. A new method of classifying prognostic comorbidity in longitudinal studies: development and validation. J Chronic Dis. 1987;40(5):373-338.

153. Frei A, Muggensturm P, Putcha N, et al. Five comorbidities reflected the health status in patients with chronic obstructive pulmonary disease: the newly developed COMCOLD index. J Clin Epidemiol. 2014;67(8):904-911.

154. Hawkins NM, Petrie MC, Macdonald MR, et al. Heart failure and chronic obstructive pulmonary disease: the quandary of beta-blockers and beta-agonists. J Am Coll Cardiol. 2011;57(21):2127-2138.

155. Celli B, Decramer M, Leimer I, Vogel U, Kesten S, Tashkin DP. Cardiovascular safety of tiotropium in patients with COPD. Chest. 2010;137(1):20-30.
156. McMurray JJ, Adamopoulos S, Anker SD, et al. ESC Guidelines for the Diagnosis and Treatment of Acute and Chronic Heart Failure 2012: the Task Force for the Diagnosis and Treatment of Acute and Chronic Heart Failure 2012 of the European Society of Cardiology. Developed in collaboration with the Heart Failure Association (HFA) of the ESC. Eur Heart J. 2012;33(14):1787-1847.

157. Van der Hooft CS, Heeringa J, Brusselle GG, et al. Corticosteroids and the risk of atrial fibrillation. Arch Intern Med. 2006;166(9): 1016-1020.

158. Walters JA, Walters EH, Wood-Baker R. Oral corticosteroids for stable chronic obstructive pulmonary disease. Cochrane Database Syst Rev. 2005;3:CD005374.

159. Huerta C, Lanes SF, Garcia Rodriguez LA. Respiratory medications and the risk of cardiac arrhythmias. Epidemiology. 2005;16(3): 360-366.

160. Page C, Cazzola M. Bifunctional drugs for the treatment of asthma and obstructive pulmonary disease. Eur Respir J. 2014;44(2): 475-482.

161. Lee DS, Markwardt S, McAvay GJ, et al. Effect of $\beta$-blockers on cardiac and pulmonary events and death in older adults with cardiovascular disease and chronic obstructive pulmonary disease. Med Care. 2014;52(3):45-51.

162. Foresi A, Cavigioli G, Signorelli G, Pozzoni MB, Olivieri D. Is the use of beta-blockers in COPD still an unresolved dilemma? Respiration. 2010;80(3):177-187.

163. Matera MG, Martuscelli E, Cazzola M. Pharmacological modulation of beta-adrenoceptor function in patients with coexisting chronic obstructive pulmonary disease and chronic heart failure. Pulm Pharmacol Ther. 2010;23(1):1-8.

164. Gottlieb SS, McCarter RJ, Vogel RA. Effect of beta-blockade on mortality among high-risk and low-risk patients after myocardial infarction. N Engl J Med. 1998;339(8):489-497.

165. Petersen H, Sood A, Meek PM, et al. Rapid lung function decline in smokers is a risk factor for COPD and is attenuated by angiotensinconverting enzyme inhibitor use. Chest. 2014;145(4):695-703.

166. Forth R, Montgomery H. ACE in COPDQ a therapeutic target? Thorax. 2003;58(7):556-558.

167. Reiner Z, Catapano AL, De Backer G, et al; ESC Committee for Practice Guidelines (CPG) 2008-2010 and 2010-2012 Committees. ESC/EAS Guidelines for the managements of dyslipidaemias: the Task Force for the managements of dyslipidaemias of the European Society of Cardiology (ESC) and the European Atherosclerosis Society (EAS). Eur Heart J. 2011;32(14):1769-1818.

168. Corsonello A, Pedone C, Corica F, et al; Gruppo Italiano di Farmacovigilanza nell'Anziano (GIFA) Investigators. Concealed renal insufficiency and adverse drug reactions in elderly hospitalized patients. Arch Intern Med. 2005;165(7):790-795.

169. Tan KH, De Cossart L, Edwards PR. Exercise training and peripheral vascular disease. Br J Surg. 2000;87(5):553-562.

170. Bennell KL, Hinman RS. A review of the clinical evidence for exercise in osteoarthritis of the hip and knee. J Sci Med Sport. 2011;14(1):4-9.

171. O'Gorman DJ, Krook A. Exercise and the treatment of diabetes and obesity. Med Clin North Am. 2011;95(5):953-969.

172. Thomas DE, Elliott EJ, Naughton GA. Exercise for type 2 diabetes mellitus. Cochrane Database Syst Rev. 2006;3:CD002968.

173. Make B, Dutro MP, Paulose-Ram R, Marton JP, Mapel DW. Undertreatment of COPD: a retrospective analysis of US managed care and Medicare patients. Int J Chron Obstruct Pulmon Dis. 2012;7: $1-9$.

174. Blanchette CM, Gross NJ, Altman P. Rising costs of COPD and potential maintenance therapy to slow the trend. Am Health Drug Benefits. 2014;7(2):98-106.

175. Anecchino C, Rossi E, Fanizza C, De Rosa M, Tognoni G, Romero M; Working Group ARNO Project. Prevalence of chronic obstructive pulmonary disease and pattern of comorbidities in a general population. Int J Chron Obstruct Pulmon Dis. 2007;2(4): 567-574. 
176. Lopez Varela MV, Montes de Oca M, Halbert RJ, et al; PLATINO Team. Sex-related differences in COPD in five Latin American cities: the PLATINO study. Eur Respir J. 2010;36(5): 1034-1041.
177. van Manen JG, Bindels PJ, Lizermans CJ, van der Zee JS, Bottema BJ, Schadé E. Prevalence of comorbidity in patients with chronic airway obstruction and controls over the age of 40. J Clin Epidemiol. 2001;54(3):287-293.

International Journal of COPD

\section{Publish your work in this journal}

The International Journal of COPD is an international, peer-reviewed journal of therapeutics and pharmacology focusing on concise rapid reporting of clinical studies and reviews in COPD. Special focus is given to the pathophysiological processes underlying the disease, intervention programs, patient focused education, and self management protocols.
Dovepress

This journal is indexed on PubMed Central, MedLine and CAS. The manuscript management system is completely online and includes a very quick and fair peer-review system, which is all easy to use. Visit http://www.dovepress.com/testimonials.php to read real quotes from published authors.

Submit your manuscript here: http://www.dovepress.com/international-journal-of-copd-journal 